\title{
Text Analysis on Personality Cultivation of Undergraduates from Perspective of Cultural Capital Theory
}

\author{
Yongjian $\mathrm{Xu}$ \\ College of Marxis m \\ Jilin Agricultural University \\ Changchun, China
}

\author{
Xiaojie Xu \\ College of Marxis m \\ Jilin Agricultural University \\ Changchun, China
}

\begin{abstract}
The cultural capital theory of Bourdieu is one of important content of his sociological theory system. The cultural capital indudes specific cultural capital, objective cultural capital and institutional cultural capital, and 3 types of cultural capital perform as cultural competence, cultural product and cultural system in formation of cultural capital of contemporary college students. The cultural capital of undergraduates plays an important role in ideological and political education of colleges and universities, and it is the significant foundation for personality cultivation of undergraduates. So the stock for cultural capital of contemporary college students will influence and decide their cultural competence.
\end{abstract}

Keywords-bourdieu; cultural capital; undergraduates; personality

\section{INTRODUCTION}

Auguste Comte, father of sociology, firstly proposed concept of cultural capital in Social Regime System. Furthermore, Pierre Bourdieu, a sociologist of France, conducted the extensive and systematic research on cultural capital, and he unscrambled the cultural capital from noneconomical perspective, which broke through previous explanation on capital from economics perspective. Bourdieu explained and analyzed capital from perspective of "field domain", proposed that the capital presented different status in different "field domain", and his division expanded the research angle of view to cultural capital.

\section{CUltural CAPIT AL THEORY OF PIERRE BOURDIEU}

Bourdieu thought that the cultural capital was formed by culture and capital, and what was called "culture" was the philosophical concept, which reflected ideology, behavior, life style of society and their materialization. What was called "capital" was the economical concept and the capital was used for value appreciation in exchange. In concept of cultural capital, culture was subject, and cultural capital was a kind of cultural interpretation for capital conducted by Bourdieu, cultural capital was the certain ideology, behavioral pattern and life style, and it was the cultural resource that could breed

[Project Sources] Research Program of Higher Education of Jilin Association for Higher Education: part of research achievements "Research on Life Value Education of Undergraduates in Colleges and Universities (Project number: JGJX2015D36). new culture and make culture resource produce further appreciation. Take culture as the capital, emphasized that cultural capital was cultural resource that can bring its culture appreciation based on the meaning of "culture can influence people", and the cultural accumulation of subject had ability of its culture promotion.

Bourdieu didn't give a clear definition for cultural capital, but he proposed 3 existing forms of cultural capital.

The first one was the specific manifestation of cultural capital, meaning that internalization is the premise for acquisition of individual cu ltural ability, and learning and time input are needed in this progress, individual must do it by themselves as well, in which alternative principle doesn't exist. The cultural capital could be acquired from certain school education and family education, once the cultural was acquired, it could transfer to their cultural wealth, and became the cultural quality of social individual, and the quality would decide the cultural competence of social individual. It included language competence, social communication ability, professional technical capability, personal behavior and ability of grasping success opportunity.

The second one was the objective manifestation of cultural capital, which was manifestation pattern of cultural product (poetry, book, picture and film and television, etc.), these products are the specific presentation of theory trace or theory, or criticis $m$ to theory, problems, etc. So cultural product was the objective form of cultural capital. The value of cultural product needed that individuals who had cultural competence to realize their own appreciation based on their cultural accumulation, and then the existing cultural resource could be transformed to capital.

The third one was the institutional manifestation of cultural capital. More generally, it existed in the certain form authorized by the certain cultural system from management department of social culture, and was an approach to control the social culture capital for management department of social culture. This kind of education background and occupation certification made owners have the value of legal guarantee, and their authentication level was higher, their holding quantity of cultural capital would be larger, cultural competence would be stronger. 


\section{COMPONENT FACTORS ON CULTURAL CAPITAL OF CONTEMPORARY COLLEGE STUDENTS}

The cultural capital is the system structure in which various interactional capital factors combine organically. The knowledge capital of undergraduates can transform to comprehensive ability capital that can promote quality and cultural competiveness of undergraduates.

\section{A. Knowledge Capital}

After entering to university campus, the first work of undergraduates is leaning various cultural courses and accumulating cultural capital. The knowledge acquired in university becomes the core of knowledge structure of undergraduates, and meanwhile, the leaning process in campus is the accumulation process of cultural capital. It requires that undergraduates should master systematical professional knowledge on related majors, and create the certain culture products during study, the acquisition of relevant diploma and certification after graduation is the reflection of institutional capital for undergraduates, and meanwhile it is the important part of their cultural capital.

\section{B. Moral Personality Capital}

The moral personality means the ideological and ethical standards since teenager period, includes world outlook, life outlook and value, and is the attitude to society, life and value. The healthy moral personality is the good spiritual motive reflected in social activities, and the guarantee of forming correct ideology; the healthy moral personality can adjust and govern the mentality and behavior of human and promote the healthy development. Furthermore, one person whether has perfect moral personality will influence his future development.

\section{Comprehensive Ability Capital}

The comprehensive ability capital means the knowledge level, moral quality, ability of controlling affairs, and strain capacity to learning and life, etc. possessed by individual. The comprehensive quality of students represents their gold content as talents, and concerns their learning situation and employment ability; as a whole, the comprehensive ability represents the quality and level of future builder of our country. Specifically, the comprehensive ability covers morality, value, character, interest, intelligence, ability and physical ability, and ability of analyzing problems, solving problems, continuous learning, organization and management, adapting to society, grasping interpersonal communication, and innovation ability, etc. The comprehensive ability capital is one of important source of accumulating cultural capital of undergraduates constantly.

\section{Habit Quality Capital}

This is capital accumulation influenced unconsciously, means habits, interest, hobby from childhood, habits, mode of thinking, life style with individual characters inherited from parents and acquired from school education, etc. It is the cultural knowledge, personal accomplishment and individual skills accumulated from social activities and communication with others in their own life experience. Specifically, it can be divided into two aspects: intellectual cultural capital, such as language style, manner, intelligence, etc., and cultural capital, which is volitional quality inherited from family, such as perseverance, braveness and confidence, character, and hardwork and self-control, etc.

\section{FUNDAMENTAL FUNCTION OF CULTURAL CAPITAL TO PERSONALITY CULTIVATION}

The cultivation and molding of undergraduates' pers onality is the specific guidance to personality development of undergraduates, it is one of important content of ideological and political education, and basic quality for integrated development of individual. The development on practice of ideological and political education based on cultural capital promotion to youthful students is the important content of cultivating wholesome and healthy personality of undergraduates, and this fundamental function reflects in education of "three outlook", ethical conduct and individuality cultivation in personality cultivation of undergraduates.

\section{A. Basic Quality of "Three Outlook" Cultivation}

The important content of spiritual civilization construction in China includes world outlook, life outlook and value (for short "three outlook") education. In teaching and theory research of colleges and universities, "three outlook" education is the important part of ideological and political education system. In order to study the function of cultural capital to cultivation of world outlook, life outlook and value, firstly, the conceptional carding and definition of "three outlook" should be taken. The cultural capital has the most fundamental function to personality cultivation of undergraduates, and it also reflects in function of "three outlook" cultivation of undergraduates firstly.

1) Cultural capital in "Three Outlook" education of undergraduates: As the important effective strength and intellectual groups in contemporary social development, the education on world outlook, life outlook and value of undergraduates is always the important content of developing deep and systematic ideological and political education in colleges and universities in China. The promotion and publicity of "three outlook" education will greatly and positively improve the personality molding, ability enhancement and mental training of contemporary college students.

As the reliable resource of undergraduates, cultural capital can help many undergraduates to form correct world outlook, life outlook and value, and closely combine the ideological and political education of undergraduates, thus realize the best effect on function and value of three outlook. In real life, the establishment of world outlook, life outlook and value is not accomplished in an action. Therefore, the formation and accumulation for cultural capital of undergraduates can play great role in promoting their cultural quality and achieving higher cultivation status.

2) Important function of cultural capital to establishment of "Three Outlook": The cultural capital has important leading function to "three outlook" of undergraduates. 
Bourdieu thought that the formation and accumulation of cultural capital was from accumulation of early family education, school education and social education. The education received by undergraduates is related to their cultural capital closely, also the important way of accumulating cultural capital, so without education, the cultural capital will become water without a source, tree without root. The cultural capital has the extremely important function for establishing correct world outlook, life outlook and value.

The cultural capital of undergraduates enriches the practice content of ideological and political education. It highlights in "three outlook" education of ideological and political education in China, and ecological ethics, economic morality and scientific and technical morality are added in "three outlook" education on the base of previous patriotism, collectivism, social morality, professional ethics and education, they have deeply rooted in brain of each undergraduate, and become the guidance of their behaviors.

\section{B. Basic Quality for Formation of Moral Character}

The moral character is a kind of quality, it internally reflects in thought and action, and guides the direction for behaviors of human. In certain sense, one's moral character will influence one's behavior, and even influence the country and society, therefore, we must pay much attention to formation of moral character of undergraduates.

1) Cultural capital to improvement on cultivation of moral character of undergraduates by means of personality education: In reality, cultivation on good moral character of undergraduates is the ultimate goal pursued by ideological and political education, while the moral character is one of factors for forming the cultural capital of undergraduates. The final goal of moral character is returning to human, and it needs combination of knowledge is action and action is knowledge" in various situations. In Avicenna, Abdelilah Fahmi, from Egypt, proposed that "all good and bad virtue are acquired. When a person has not formed the established virtue, he will cultivate the virtue by himself. While when the heart of human changes in some certain moral character, he can also abandon it and tend to its opposite depending on his will. Since the realization of moral character goal should depend on personality education, the promotion of personality education must rely on the important resource and conditional foundation of cultural capital.

2) Cultural capital to improvement of moral environment: Moral environ ment is a comprehensive concept, covers family moral environment, unit moral environment and public moral environment, etc., and the cultural capital plays an important role in integral moral environment of society.

The family moral environment mainly means the overall education background, economic foundation, and artistic appreciation of family, and the molding of family cultural capital is important, since the moral atmosphere of family will influence the entire life of human, and always make a deep sear for one's virtue. Speaking rom unit moral environment, it is composed of "hard environment" and "soft environment", "hard environment" mainly includes infrastructure, building, historical sites, and human landscape; "soft environment" mainly is the moral environ ment of spirit level, and the cultural capital of members of society has the important function to improvement of moral environment. The increment and appreciation of cultural quality can improve the integral civilization level of subject, change the behavioral pattern of members of society, thus change behavioral pattern of human and improve moral environment. The key of this process is the improvement of cultural quality of human.

\section{Basic Quality for Personality Formation of Human}

The personality reflects specific temperament, character and morals, and ability of human, so the personality status represents civilization of society. The development situation of pers onality of contemporary college students reflects historical trend and civilization development state of era. Engels had said "character of era mainly is character of youth." Undergraduates are subject promoting historical development of contemporary society, and the social development and progress are closely related to cultural science and technology level possessed by undergraduates. The free and all-around development of personality will become historical trend of future development of modern society, and is also a distinguishing feature of human development in modern society. Therefore, the comprehensive promotion on free and all-around development of personality of youthful students will be the major initiatives of benefiting numerous people and accelerating rapid development of society.

1) Cultural capital to improvement on personality cultivation of undergraduates: Personality is the sum of psychological characteristics of each person formed by thought, emotion, physical power, intelligence, character and will, etc., and is a complex and interactional synthesis. The characters on personality of undergraduates mainly covers: subjectivity, shows that they can improve and perfect themselves positively and initiatively; peculiarity, mainly means the relative difference between intelligence and nonintelligence in different subjects; social orientation, the essence of undergraduates groups is their sociality.

The personality of undergraduates is the specific reflection of cultural capital state, contemporary college students are full of personality extremely, so the personality education to undergraduates not only should respect their personality development, but also should consider requirements of social development, in order to realize organic unification of personality and sociality, in this way, men of talent will come out in succession and develop rapidly in our society.

2) Cultural capital to personality cultivation of undergraduates by means of campus culture: As a whole, the campus culture is the objective reflection on appreciation of cultural capital, campus culture is culture in high level and quality, so campus culture plays a role of cultivating undergraduates' personality unconsciously. On the one hand, campus life has strong permeability. It influences the growth and development, improvement of moral quality of 
undergraduates unconsciously. On the other hand, it has durability and selectivity, plays prominent role for personality formation of undergraduates.

In cultural construction of campus, the cultural capital not only can make contribution to personality cultivation of undergraduates in moral education, but also can play an important role for personality molding of undergraduates in intellectual education. It not just is helpful for digestion of various knowledge, more than is helpful for cultivation of creative personality.

\section{CONCLUSION}

Therefore, the accumulation and reproduction of cultural capital should be paid more attention, and organization of rich campus activities can provide good environment and platform for creating personality of undergraduates. The practical activities are specific pattern of personality generation and existence, because different pers onalities will be created truly only by means of practical activities. The social practical activities should be paid more attention to improve undergraduates in practice, which is the main channel of developing and utilizing cultural capital of undergraduates, and the important way of cultivating personality of undergraduates.

\section{REFERENCES}

[1] Yaming Bao, Cultural Capital and Social alchemy [M], Shanghai: Shanghai People's Publishing House, 1997.

[2] Xian Yan, Research on Bourdieu's Cultural Capital Theory and Practical Value [D]"Changchun: Northeast Normal University, 2006.

[3] Fang Liu. Cultural Capital and Employment Choice of Contemporary College Students [D]: Master's Thesis. Changchun: Northeast Normal University, 2008. 